\title{
Original Article \\ Garlic Oil Alleviates MAPKs- and IL-6-mediated Diabetes-related Cardiac Hypertrophy in STZ-induced DM Rats
}

\author{
Sheng-Huang Chang, ${ }^{1,2}$ Chung-Jung Liu, ${ }^{3,4,5}$ Chia-Hua Kuo, ${ }^{6}$ Hong Chen, ${ }^{2}$ Wen-Yuan Lin, ${ }^{7}$ \\ Kun-Yu Teng, ${ }^{8}$ Sheng-Wei Chang, ${ }^{8}$ Chang-Hai Tsai, ${ }^{9}$ Fuu-Jen Tsai, ${ }^{10}$ Chih-Yang Huang, ${ }^{3,10,11}$ \\ Bor-Show Tzang, ${ }^{1,13}$ and Wei-Wen Kuo ${ }^{8}$
}

${ }^{1}$ Institute of Biochemistry and Biotechnology, Chung Shan Medical University, Taichung, Taiwan

${ }^{2}$ Tsao-Tun Psychiatric Center, Department of Health, Executive Yuan, Taiwan

${ }^{3}$ Institute of Basic Medical Science, China Medical University, Taichung, Taiwan

${ }^{4}$ Division of Environmental Health and Occupational Medicine, National Health Research Institutes, Miaoli County, Taiwan

${ }^{5}$ Division of Gastroenterology, Department of Internal Medicine, Kaohsiung Medical University Hospital, Kaohsiung, Taiwan

${ }^{6}$ Laboratory of Exercise Biochemistry, Taipei Physical Education College, Taipei, Taiwan

${ }^{7}$ Department of Family Medicine, China Medical University and Hospital, Taiwan

${ }^{8}$ Department of Biological Science and Technology, China Medical University, Taiwan

${ }^{9}$ Department of Healthcare Administration, Asia University, Taiwan

${ }^{10}$ Graduate Institute of Chinese Medical Science, China Medical University, Taiwan

${ }^{11}$ Department of Health and Nutrition Biotechnology, Asia University, Taiwan

${ }^{12}$ Department of Biochemistry, School of Medicine, Chung Shan Medical University, Taiwan

${ }^{13}$ Clinical Laboratory, Chung Shan Medical University Hospital, Taichung, Taiwan

Correspondence should be addressed to Wei-Wen Kuo,wwkuo@mail.cmu.edu.tw

Received 19 February 2009; Accepted 25 May 2010

Copyright (C) 2011 Sheng-Huang Chang et al. This is an open access article distributed under the Creative Commons Attribution License, which permits unrestricted use, distribution, and reproduction in any medium, provided the original work is properly cited.

Garlic oil has been reported to protect the cardiovascular system; however, the effects and mechanisms behind the cardioprotection of garlic oil on diabetes-induced cardiaomyopathy are unclear. In this study, we used streptozotocin (STZ)-induced diabetic rats to investigate whether garlic oil could protect the heart from diabetes-induced cardiomyopathy. Wistar STZ-induced diabetic rats received garlic oil $\left(0,10,50\right.$ or $100 \mathrm{mg} \mathrm{kg}^{-1}$ body weight $)$ by gastric gavage every 2 days for 16 days. Normal rats without diabetes were used as control. Cardiac contractile dysfunction and cardiac pathologic hypertrophy responses were observed in diabetic rat hearts. Cardiac function was examined using echocardiography. In addition to cardiac hypertrophy-related mitogen-activated protein kinases (MAPK) pathways (e.g., p38, c-Jun N-terminal kinases (JNK) and extracellularly responsive kinase (ERK1/2)), the IL-6/MEK5/ERK5 signaling pathway was greatly activated in the diabetic rat hearts, which contributes to the up-regulation of cardiac pathologic hypertrophy markers including atrial natriuretic peptide (ANP) and B-type natriuretic peptide (BNP), and leads to cardiac contractile dysfunction. Garlic oil treatment significantly inhibited the up-regulation in MAPK (e.g., p38, JNK and ERK1/2) and IL-6/MEK5/ERK5 signaling pathways in the diabetic rat hearts, reducing the levels of cardiac pathologic hypertrophy markers such as ANP and BNP, and improving the cardiac contractile function. Collectively, data from these studies demonstrate that garlic oil shows the potential cardioprotective effects for protecting heart from diabetic cardiomyopathy.

\section{Introduction}

Diabetes mellitus (DM) is one of the major risk factors for cardiovascular disease development, accounting for $80 \%$ of all diabetic mortality [1]. In addition, the mortality of cardiac disease in patients with diabetes is 2 - to 4 -fold higher than that in subjects without diabetes [2]. The destruction of car- diac function has been well documented in both clinical and experimental diabetes [3-5]. Several pathological processes may initiate myocyte injury and myocardial dysfunction in patients with diabetes. Diabetic cardiomyopathy, characterized by cardiac hypertrophy and the presence of diastolic and/or systolic contractile dysfunction, eventually leads to heart failure [6]. 
Cardiac hypertrophy is defined as an enlargement of the heart with the increase in volume of cardiomyocyte cell. Cardiac hypertrophy is a multi-step process that occurs in response to various pathological stimuli such as myocardial infarction (MI), hypertension, valvular insufficiency, infectious agents and endocrine disorders $[7,8]$. Under these stimuli, hypertrophic growth of myocardium is required to adapt to the increased work load of the heart and/or preserve the heart pump function by increasing muscle mass $[8,9]$. Cardiac pathological hypertrophy is characterized by an increase in cell size, sarcomere reorganization and activation of the fetal genes including atrial natriuretic peptide (ANP), B-type natriuretic peptide (BNP), $\beta$-myosin heavy chain and skeletal alpha actin $[10,11]$. Prolonged hypertrophic status has been reported to be associated with the decompensation of heart function, the development of heart failure and sudden death in humans [12-14]. Epidemiological studies have showed that cardiac hypertrophy is an independent risk factor for cardiac morbidity and mortality $[15,16]$.

Cardiac hypertrophy response is typically induced by active membrane-bound receptors that lead to the activation of intracellular signaling pathways through multiple GTPase proteins, kinases and phosphatases. A large number of studies have been dedicated to exploring the molecular mechanisms behind the hypertrophic response of myocardium [17]. Mitogen-activated protein kinases (MAPKs) include three major subfamilies such as the extracellularly responsive kinases (ERKs), the c-Jun N-terminal kinases (JNKs), also known as stress-activated protein kinases (SAPKs), and the p38 MAPKs [18]. In the heart, MAPK signaling pathways have been reported to participate in the development of cardiac hypertrophy in response to stimuli $[10,19$, 20]. For example, depletion of ERK1/2 signaling pathway using antisense oligodeoxynucleotides significantly attenuated phenylephrine (PE)-induced cardiomyocyte hypertrophy in culture [21]. MEK1 inhibitor U0126 greatly inhibited both endothelin-1 (ET-1) and PE-induced cardiomyocyte hypertrophy in vitro [22]. p38-MAPK was observed in pressure overload [23, 24], and ET-1/PE stimulation [25], and the increased p38-MAPK activity has been showed to involve in many cardiovascular diseases such as hypertension, cardiac hypertrophy, myocardial ischemia and heart failure [26]. In cardiomyocytes, the increased activity of JNK is sufficient to induce cardiomyocyte hypertrophy in response to mechanical stretching [27] or hypertrophic agonists such as ET-1 [28], PE [29] or angiotensin II (Ang II) [30]. Down-regulation of JNK activity by dominantnegative MKK4 mutant or MEKK1 disruption significantly reduced the hypertrophic response induced by ET-1 [28], pressure overloading [31] and ischemia/reperfusion [32]. Elevated intracardiac interleukin-6 (IL-6) is reported and causes cardiac hypertrophy through the IL-6 signal transducing receptor component, glycoprotein 130 (gp130), which eventually leads to heart failure (HF) [33]. The activated MEK5/ERK5 signaling pathway by IL-6 family cytokines, leukemia inhibitory factor (LIF) and carddiotrophin-1 (CT1) has been shown to result in the serial assembly of sarcomeres and eccentric cardiac hypertrophy [34].
Garlic (Allium sativum) has played important dietary and medicinal roles for centuries. Due to its exhibition of inhibiting enzymes involved in lipid synthesis, decreasing platelet aggregation, preventing lipid peroxidation of oxidized erythrocytes and low-density lipoprotein, increasing antioxidant status and inhibiting angiotension-converting enzyme [35-38], today the medicinal use of garlic is widespread and growing. The main property of garlic for therapeutic effects is as an effective antioxidant against oxidative damage in cardiovascular diseases [39]. In addition, according to Ryan's report [40], garlic is also the most commonly used alternative medication by diabetic patients. The antihyperglycemic effect of garlic has been reported in several studies [41-44]. It was also reported that garlic can improve hyperglycemia in diabetic patients [45]. However, information about the effects of garlic on the diabetic heart is very limited.

Therefore, we hypothesize that cardiac contractile dysfunction and cardiac pathologic hypertrophy induced by diabetes can be alleviated by garlic oil supplement. The results demonstrated that garlic oil treatment down-regulates activities of MAPKs (e.g., p38, JNK and ERK1/2) and IL6/MEK5/ERK5 signaling pathways, and reduces expressions of pathologic hypertrophy response genes such as ANP and $\mathrm{BNP}$, which contributes to the improvement of cardiac contractile function.

\section{Methods}

2.1. Garlic Oil Preparation. Garlic oil was prepared as described [46]. Briefly, a steam distillation technique was used, and the final product contained major garlic oil essential components, including diallyl disulfide, diallyl trisulfide, diallyl sulfide and minor amounts of many other volatile compounds.

2.2. Animal Model and Treatments. Male Wistar rats (4 weeks old) were purchased from the National Animal Breeding and Research Center (Taipei, Taiwan). The animals were kept under a 12-h light-dark cycle and ambient temperature was maintained at $25^{\circ} \mathrm{C}$. Animals were given free access to water and standard laboratory chow (Lab Diet 5001; PMI Nutrition International Inc., Brentwood, MO, USA). Housing conditions and experimental procedures were performed according to the NIH Guide for the Care and Use of Laboratory Animals and all protocols were approved by the Institutional Animal Care and Use Committee of Chung Shan Medical University, Taichung, Taiwan. After 1 week of acclimatization, diabetes was induced by injection of streptozotocin (STZ, $65 \mathrm{mg} \mathrm{kg}^{-1}$ body weight (BW) in citrate buffer, $\mathrm{pH} 4.5$ ) into a lateral tail vein [47]. Control rats were injected with the same volume of citrate buffer. After 3 days of injection, animals in which diabetes had been successfully induced were randomly separated into four groups and fed 10,50 and $100 \mathrm{mg} \mathrm{kg}^{-1}$ BW garlic oil or vehicle (corn oil, $2 \mathrm{ml} \mathrm{kg}{ }^{-1} \mathrm{BW}$ ) for 16 days. It was done by daily oral gavages in the vehicle corn oil. The nondiabetic control animals were fed corn oil $\left(2 \mathrm{ml} \mathrm{kg}^{-1}\right.$ BW). After 16 days of treatment, all animals were anesthetized and echocardiography was 
performed. Then, they were sacrificed and their hearts were removed for further analysis.

2.3. In Vivo Cardiac Function. Transthoracic echocardiograms were performed at heart rates (HRs) of 300-450 beats per minute in rats anesthetized with isoflurane mixed with $\mathrm{O}_{2}$ at flow rate of 5 psi before and 16 days after the garlic oil feeding by an echo machine (Vivid i, 10S transducer, GE Medical Systems, Milwaukee, WI, USA) using a $4-11 \mathrm{MHz}$ phase-array transducer. M-mode images were obtained in the parasternal long- and short-axis views of the left ventricle. Left ventricular end-diastolic diameter (LVEDD), left ventricular end-systolic diameter (LVESD) and posterior wall thickness (PWT) were determined for five cardiac cycles and averaged. The percentage of LV fractional shortening $(\mathrm{FS}, \%)$ was calculated as ((LVEDD - LVESD)/LVEDD) $\times$ 100 (\%). Left ventricular end diastolic volume (LVEDV) and left ventricular end systolic volume (LVESV) were used to calculate ejection fraction $(\mathrm{EF}, \%)=((\mathrm{LVEDV}-$ LVESV)/LVEDV) $\times 100(\%)$. LV mass was calculated as 1.855 $\times((\text { LVEDD }+ \text { PW + intraventricular septal thickness (IVS }))^{3}$ - (LVEDD)) (mg) and cardiac output (CO) was calculated as stroke volume $\times \mathrm{HR}\left(\mathrm{lmin}^{-1}\right)$.

2.4. Tissue Extraction. The left ventricle samples were homogenized for protein extract in a PBS buffer $(0.14 \mathrm{M} \mathrm{NaCl}$, $3 \mathrm{mM} \mathrm{KCl}, 1.4 \mathrm{mM} \mathrm{KH}_{2} \mathrm{PO}_{4}, 14 \mathrm{mM} \mathrm{K}_{2} \mathrm{HPO}_{4}$ ) at a concentration of $1 \mathrm{mg}$ tissue $/ 10 \mu \mathrm{l}$ PBS for $5 \mathrm{~min}$. The homogenates were placed on ice for $10 \mathrm{~min}$ and then centrifuged at $11000 \mathrm{~g}$ for $30 \mathrm{~min}$. The supernatant were collected and stored at $-70^{\circ} \mathrm{C}$ for further analysis.

2.5. Protein Contents. The protein content of cardiac tissue extract was analyzed using the Bradford protein assay [48] using the protein-dye kit (Bio-Rad, Richmond, CA, USA). A commercially available bovine serum albumin (Sigma Chemical, St Louis, MO, USA) was used as a standard solution. Changes in optical density were monitored at $595 \mathrm{~nm}$.

2.6. Electrophoresis and Western Blot. SDS-PAGE was carried out as described using $10 \%$ polyacrylamide gels. After the electrophoresis of samples at $140 \mathrm{~V}$ for $3.5 \mathrm{~h}$, the gels were equilibrated for $15 \mathrm{~min}$ in $25 \mathrm{mM}$ Tris- $\mathrm{HCl}, \mathrm{pH} 8.3$, containing $192 \mathrm{mM}$ glycine and 20\% (V/V) methanol. Electrophoresed proteins were transferred to nitrocellulose paper (Amersham, Hybond-C Extra Supported, 0.45 Micro) using a Hoefer Scientific Instruments Transphor Units at $100 \mathrm{~mA}$ for $14 \mathrm{~h}$. Nitrocellulose papers were incubated for $2 \mathrm{~h}$ in blocking buffer containing $100 \mathrm{mM}$ Tris- $\mathrm{HCl}$, $\mathrm{pH} 7.5,0.9 \%(\mathrm{w} / \mathrm{v}) \mathrm{NaCl}, 0.1 \%(\mathrm{v} / \mathrm{v})$ fetal bovine serum. Monoclonal antibodies (Transduction Laboratories) were diluted $(1: 1000)$ in buffer containing $100 \mathrm{mM}$ Tris- $\mathrm{HCl}$, $\mathrm{pH} 7.5,0.9 \%(\mathrm{w} / \mathrm{v}) \mathrm{NaCl}, 0.1 \%(\mathrm{v} / \mathrm{v})$ Tween-20 and $1 \%$ $(\mathrm{v} / \mathrm{v})$ fetal bovine serum. Incubations were performed for $3.5 \mathrm{~h}$. The immunoblots were washed three times in blotting buffer for $10 \mathrm{~min}$ and then immersed in the second antibody solution containing alkaline phosphatase goat anti-rabbit immunoglobulin G (dilution $1: 2000$ ) (Promega) for $1 \mathrm{~h}$. The filters were then washed three times in blotting buffer for $10 \mathrm{~min}$. Color development was presented in a $20 \mathrm{ml}$ mixture consisting of $7 \mathrm{mg}$ nitro blue tetrazolium, $5 \mathrm{mg}$ 5-bromo-4-chloro-3-indolyl-phosphate, $100 \mathrm{mM} \mathrm{NaCl}$ and $5 \mathrm{mM} \mathrm{MgCl}_{2}$ in $100 \mathrm{mM}$ Tris-HCl, pH 9.5. Signal intensity was quantitated using a PhosphoImager. $\alpha$-Tubulin was used as a loading control.

2.7. Statistical Analysis. Statistical differences were examined by one-way analysis of variance. $P<.05$ was considered statistically significant. Data were expressed as mean $\pm \mathrm{SE}$.

\section{Results}

3.1. Improvement in Cardiac Contractile Dysfunction in Diabetic Rats in Response to Garlic Oil Feeding. In order to assess cardiac function and dimension in vivo, we performed echocardiography on diabetic and normal control rats. In addition to significantly high blood glucose induced in diabetic rats, all of the animals with or without STZ-induced diabetes showed a normal appearance and had a normal global cardiac structure and function at Day 0 of induction (Table 1). After 16 days of induction, compared to control group blood glucose increased much more higher and the BW, HR and CO decreased in all diabetic animal groups. The percentage of FS and EF, calculated from the LVEDD or LVEDV and LVESD or LVESV, typically representing cardiac contractile function in rat hearts were largely decreased in diabetic rat hearts. Garlic oil supplement increased HR, CO, $\mathrm{FS} \%$ and $\mathrm{EF} \%$ in a dose-dependent manner in diabetic hearts. The BW and blood glucose exhibited unchanged after garlic oil treatment between the four groups of diabetic rats. Figure 1 shows the echocardiologic M-mode of left ventricular dimensions from rat hearts in both control and diabetic rats fed with different doses of garlic oil. Collectively, garlic oil attenuates the impaired cardiac contractility, and decreased $\mathrm{CO}$ and $\mathrm{HR}$ in diabetic rat hearts.

The degree of cardiac hypertrophy in diabetic rats was assessed using the ratio of left ventricle mass (LVM) to tibia length (TL). Although the degree of hypertrophy was higher in diabetic rats than in control rats, the ratio of LVM to TL did not differ between the four groups of diabetic rats.

3.2. The Activation of Cardiac Hypertrophy-related MAPKs (p38, JNK and ERK1/2) in the Diabetic Rat Hearts was Reduced by Garlic Oil Supplement. To further identify which signal transduction pathway(s) was involved in the mechanism behind diabetes-induced cardiac hypertrophy, we detected the phosphorylation/activation of cardiac hypertrophy-related MAPKs including p38, JNK and ERK1/2 in left ventricle from the diabetic rat hearts. We found that phosphorylated p38 is significantly increased by $\sim 5.74$-fold; phosphorylated JNK is significantly increased by $\sim 4.32$-fold; phosphorylated ERK1/2 is significantly increased by $\sim 5.03$ fold (Figure 2). Interestingly, the diabetes-induced activation of MAPKs (e.g., p38, JNK and ERK1/2) in the diabetic rat hearts was notably reduced by garlic oil supplement $(10,50$ and $\left.100 \mathrm{mg} \mathrm{kg}^{-1} \mathrm{BW}\right)$.

3.3. The Up-regulation of Intracardiac IL-6 Expression in the Diabetic Rat Hearts was Reduced by Garlic Oil Supplement. Overexpression of IL-6 in the myocardium in acute MI 


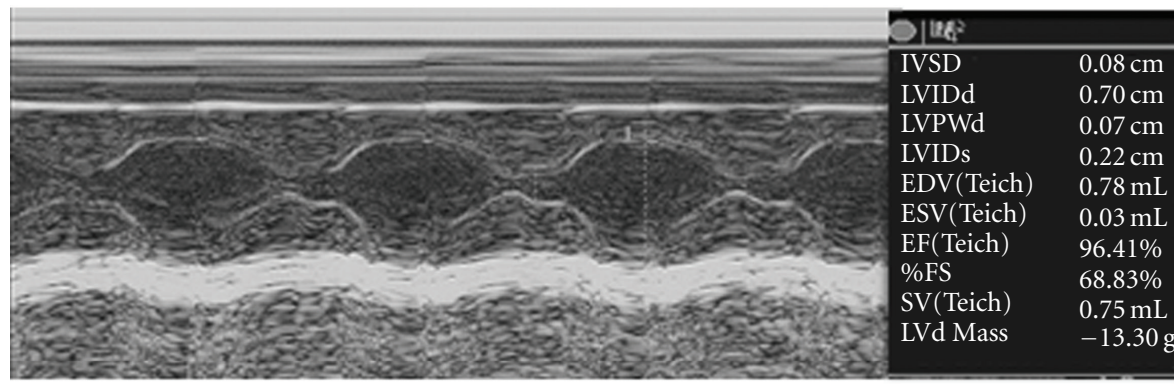

Control

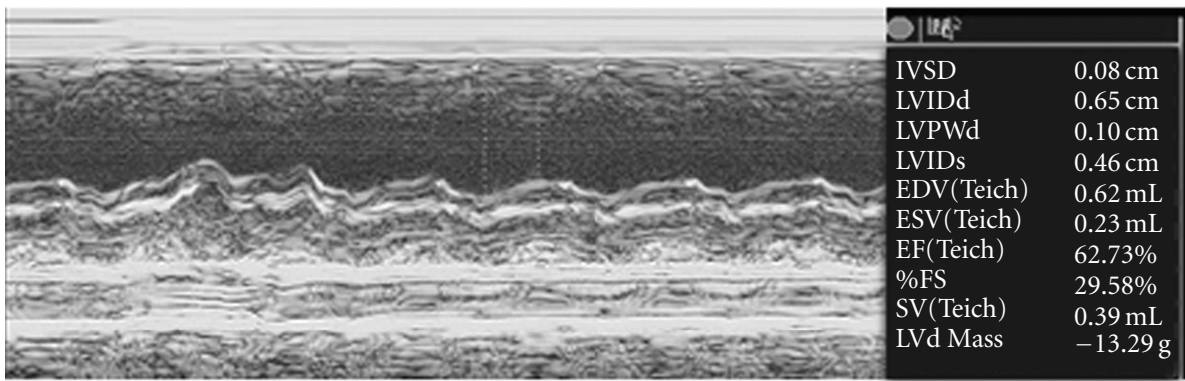

GO-0

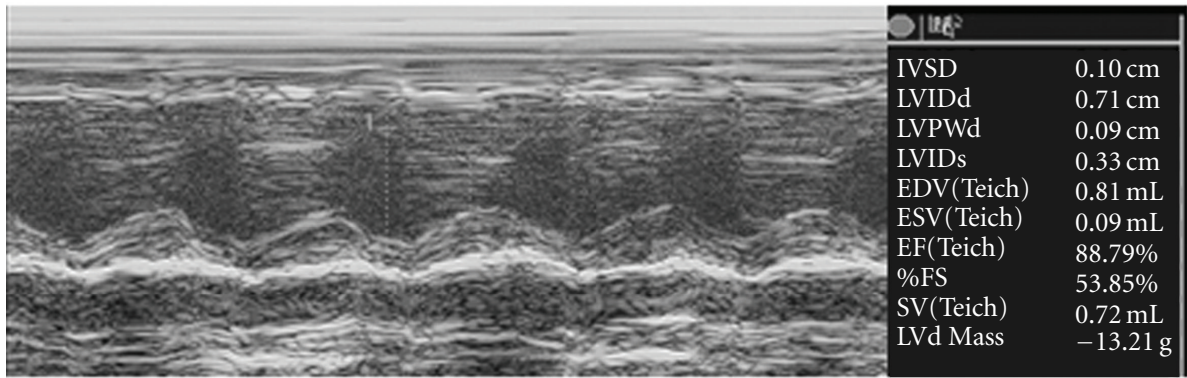

GO-10

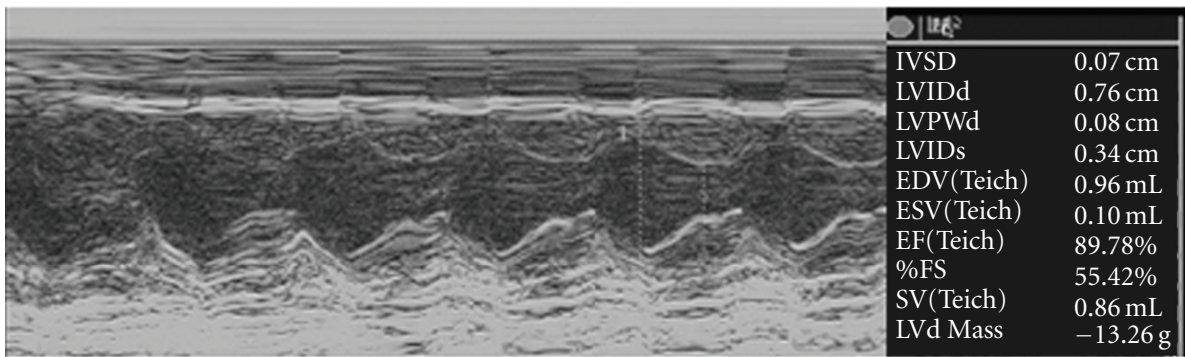

GO-50

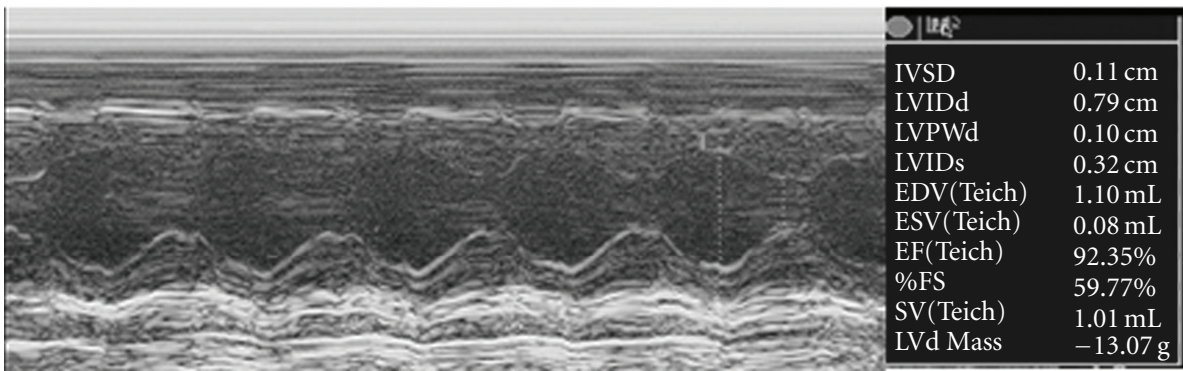

GO-1000

Figure 1: Representative echocardiographic M-mode images from at least four cardiac contractile cycles of control and diabetic rat hearts. GO- $0,-10,-50$ and -100 represent the doses of $0,10,50$ and $100 \mathrm{mg}$ garlic oil per kg BW.

(AMI) appears to be associated with the mechanism of cardiac hypertrophy [49]. The left ventricles from diabetic rat hearts showed a significant protein level of IL-6, compared to the control group (Figure 3 ). On supplementing garlic oil (10, 50 and $\left.100 \mathrm{mg} \mathrm{kg}^{-1} \mathrm{BW}\right)$ to the diabetic rats, we found that intracardiac IL-6 expression was reduced in a dosedependent manner.

3.4. Garlic Oil Supplement Reduces Expression of MEK5 and ERK5 in the Diabetic Rat Hearts. Activated MEK5/ERK5 

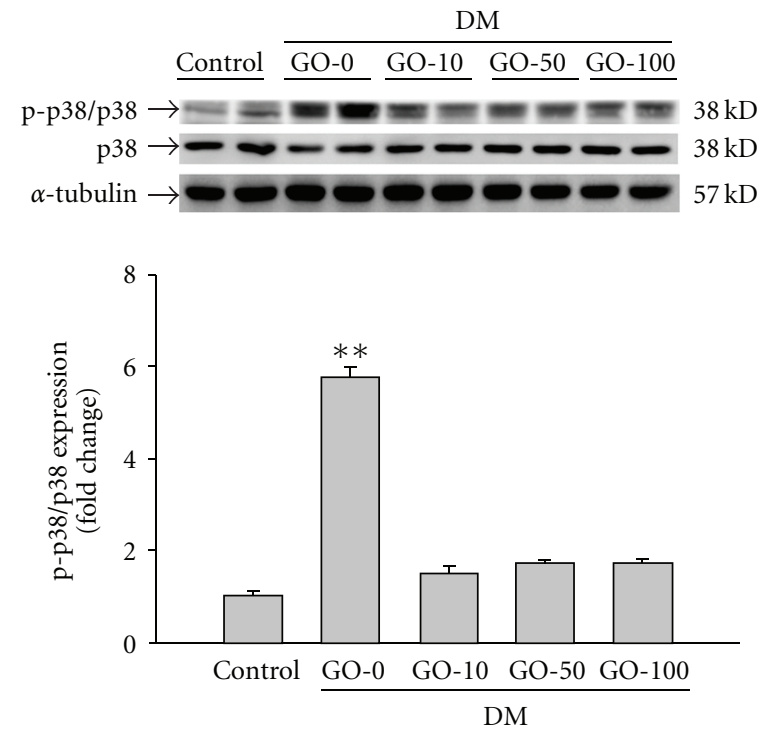

p-p38/p38
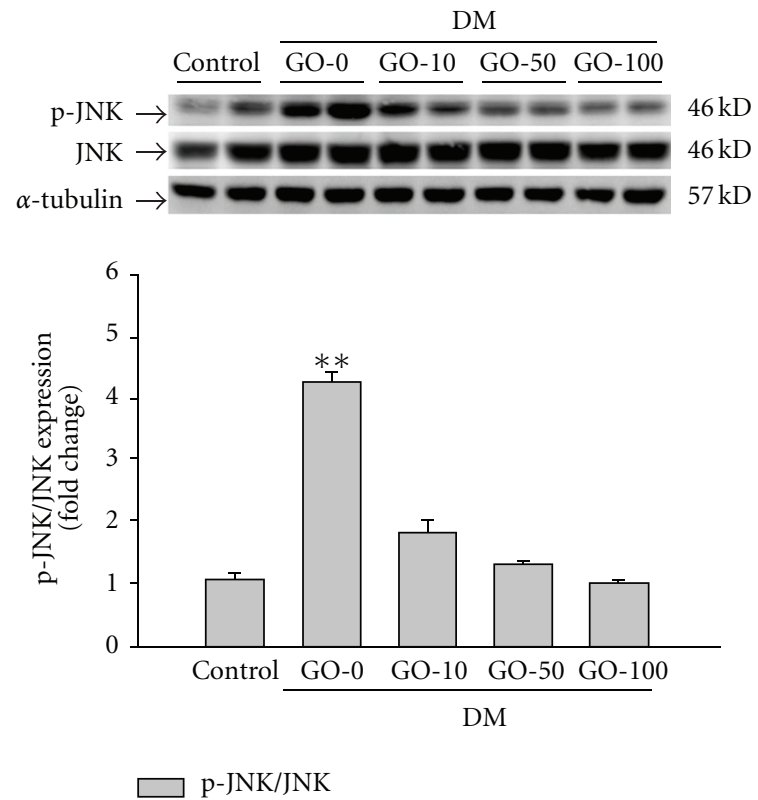

(b)
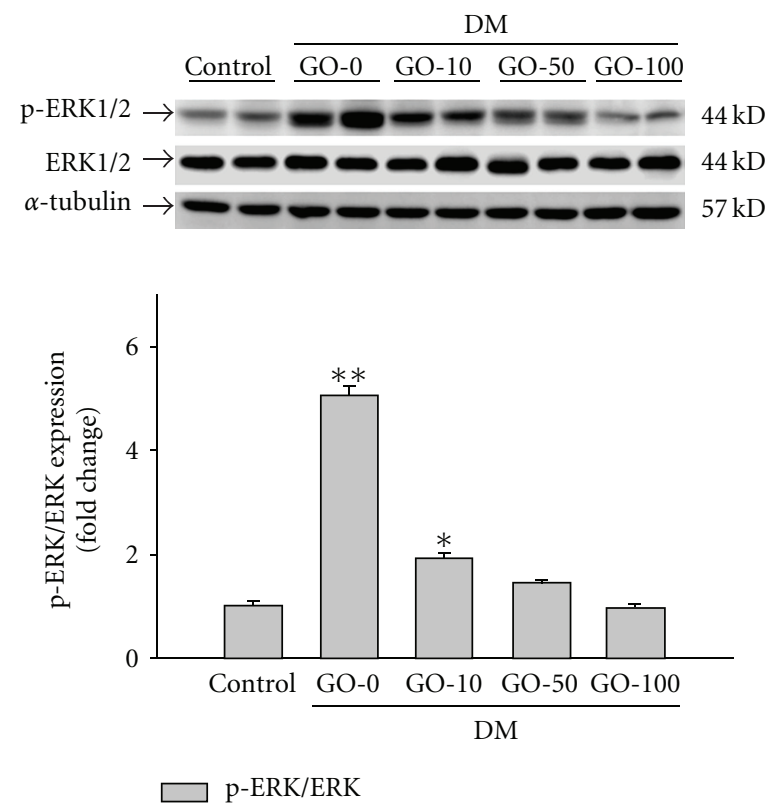

(c)

FIGURE 2: Detection of (a) phosphorylated p38, (b) phosphorylated JNK and (c) phosphorylated ERK1/2 protein levels from the left ventricles in control and diabetic rats, analyzed by western blotting. GO-0, -10, -50 and -100 represent the doses of $0,10,50$ and $100 \mathrm{mg}$ garlic oil per kg BW. Signal intensity was quantitated using a PhosphoImager. Equal loading was assessed with an anti $\alpha$-tubulin antibody. The average result $\pm \mathrm{SE}$ of three independent experiments is shown. ${ }^{*} P<.05,{ }^{*} P<.01$ represent significant differences from control group.

signaling pathway by IL-6 family cytokines has been reported to lead to the development of eccentric cardiac hypertrophy [34]. In this study, overexpression of MEK5 was detected in the diabetic rat hearts (Figure 4). The downstream
ERK5 was also significantly up-regulated in both protein expression (Figure 5(a)) and protein activation (Figure 5(b)) in the diabetic rat hearts. The results suggested that the activated MEK5/ERK5 signaling pathway participates in the 
TABLE 1: Physiological and echocardiographic parameters in rat hearts.

\begin{tabular}{|c|c|c|c|c|c|}
\hline & \multirow{2}{*}{ Control } & \multicolumn{4}{|c|}{$\mathrm{DM}$} \\
\hline & & GO-0 & GO-10 & GO-50 & GO-100 \\
\hline \multicolumn{6}{|l|}{ At basal level } \\
\hline BW (g) & $189.1 \pm 14.4$ & $153.0 \pm 14.1^{*}$ & $138.5 \pm 17.5^{*}$ & $165.0 \pm 15.0^{*}$ & $154.5 \pm 11.5^{*}$ \\
\hline Blood glucose $\left(\mathrm{mg} \mathrm{dl}^{-1}\right)$ & $73.8 \pm 6.5$ & $269.2 \pm 59.8^{*}$ & $215.0 \pm 42.3^{*}$ & $256.8 \pm 44.5^{*}$ & $218.3 \pm 49.5^{*}$ \\
\hline HR (beats/min) & $415.7 \pm 10.5$ & $400.0 \pm 22.5$ & $397.4 \pm 29.0$ & $418.8 \pm 39.1$ & $392.4 \pm 21.3$ \\
\hline LVEDD (mm) & $5.70 \pm 0.54$ & $5.29 \pm 0.38$ & $6.10 \pm 0.75$ & $5.36 \pm 0.43$ & $6.07 \pm 0.62$ \\
\hline LVESD (mm) & $2.60 \pm 0.29$ & $2.61 \pm 0.03$ & $2.95 \pm 0.51$ & $2.68 \pm 0.29$ & $3.11 \pm 0.28$ \\
\hline FS $(\%)$ & $49.8 \pm 2.0$ & $48.6 \pm 3.5$ & $49.3 \pm 4.0$ & $48.0 \pm 2.1$ & $49.6 \pm 3.9$ \\
\hline $\mathrm{EF}(\%)$ & $87.6 \pm 0.9$ & $86.7 \pm 2.9$ & $86.7 \pm 3.5$ & $87.4 \pm 1.3$ & $85.6 \pm 3.0$ \\
\hline $\mathrm{CO}\left(1 \mathrm{~min}^{-1}\right)$ & $0.20 \pm 0.05$ & $0.19 \pm 0.08$ & $0.20 \pm 0.06$ & $0.19 \pm 0.02$ & $0.19 \pm 0.01$ \\
\hline LVM (mg) & $13.22 \pm 0.05$ & $13.29 \pm 0.01$ & $13.55 \pm 0.03$ & $13.42 \pm 0.02$ & $13.50 \pm 0.07$ \\
\hline \multicolumn{6}{|c|}{ After 16-day feeding of different doses of garlic oil } \\
\hline BW (g) & $331.3 \pm 10.5$ & $225.0 \pm 14.4^{*}$ & $155.0 \pm 20.2^{*}$ & $202.5 \pm 30.3^{*}$ & $212.5 \pm 21.7^{*}$ \\
\hline Blood glucose $\left(\mathrm{mg} \mathrm{dl}^{-1}\right)$ & $96.0 \pm 7.4$ & $412.0 \pm 12.7^{*}$ & $423.5 \pm 7.8^{*}$ & $467.5 \pm 19.3^{*}$ & $453.8 \pm 18.3^{*}$ \\
\hline HR (beats/min) & $413.5 \pm 1.4$ & $279.0 \pm 10.2^{*}$ & $323.0 \pm 1.6^{*}$ & $364.5 \pm 26.8^{\#}$ & $439.7 \pm 13.6^{\#}$ \\
\hline $\operatorname{LVEDD}(\mathrm{mm})$ & $6.65 \pm 0.2$ & $6.93 \pm 0.23$ & $7.70 \pm 0.17^{*}$ & $7.45 \pm 0.29$ & $7.65 \pm 0.29^{*}$ \\
\hline LVESD (mm) & $2.45 \pm 0.14$ & $4.60 \pm 0.01^{*}$ & $4.65 \pm 0.29^{*}$ & $4.15 \pm 0.87^{*, \#}$ & $3.30 \pm 0.58^{*, \#}$ \\
\hline $\mathrm{FS}(\%)$ & $62.6 \pm 3.6$ & $33.5 \pm 2.3^{*}$ & $39.4 \pm 0.8^{*}$ & $44.2 \pm 0.9^{*}$ & $57.6 \pm 1.3^{\#}$ \\
\hline $\mathrm{EF}(\%)$ & $93.4 \pm 1.7$ & $68.0 \pm 3.0^{*}$ & $75.6 \pm 0.8^{*}$ & $80.5 \pm 0.9^{*, \#}$ & $90.8 \pm 0.8^{\#}$ \\
\hline $\mathrm{CO}\left(1 \min ^{-1}\right)$ & $0.15 \pm 0.66$ & $0.13 \pm 0.38$ & $0.25 \pm 0.17$ & $0.23 \pm 0.01$ & $0.37 \pm 0.03^{*, \#}$ \\
\hline LVM (mg) & $13.27 \pm 0.17$ & $13.21 \pm 0.04$ & $13.21 \pm 0.04$ & $13.17 \pm 0.01$ & $13.16 \pm 0.06$ \\
\hline LVM/TL $\left(\mathrm{mg} \mathrm{mm}^{-1}\right)$ & $0.329 \pm 0.001$ & $0.413 \pm 0.009^{*}$ & $0.358 \pm 0.019$ & $0.343 \pm 0.013^{\#}$ & $0.323 \pm 0.002^{\#}$ \\
\hline
\end{tabular}

Results are mean \pm SEM.

${ }^{*} P<.05$ versus with control group. ${ }^{\#} P<.05$ versus with GO-0 group ( $n=6$ rats in each group).
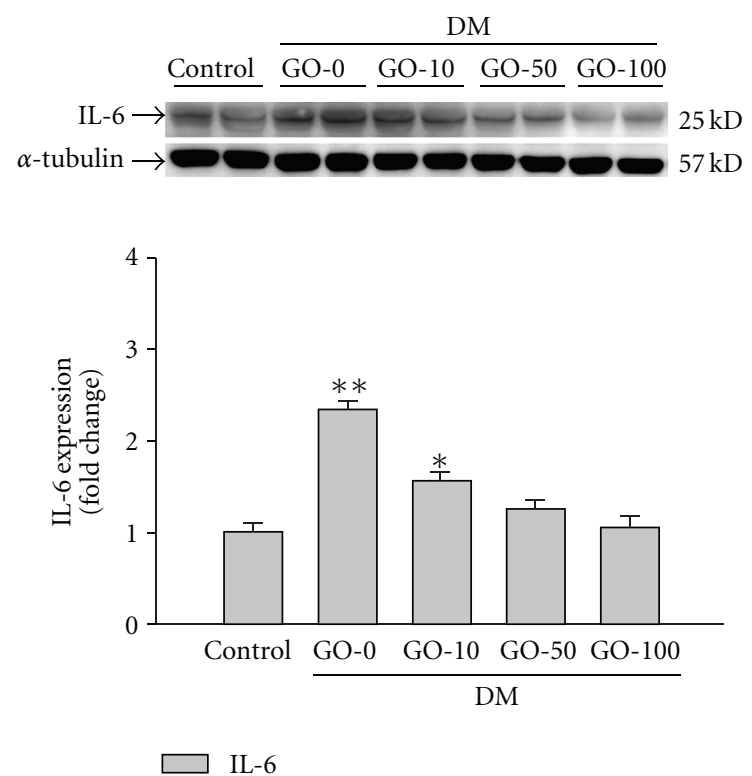

Figure 3: Detection of IL-6 protein levels from the left ventricles in control and diabetic rats, analyzed by western blotting. GO-0, -10, -50 -and -100 represent the doses of $0,10,50$ and $100 \mathrm{mg}$ garlic oil per kg BW. Signal intensity was quantitated using a PhosphoImager. Equal loading was assessed with an anti $\alpha$-tubulin antibody. The average result \pm SE of three independent experiments is shown. ${ }^{*} P<.05,{ }^{* *} P<.01$ represent significant differences from control group.
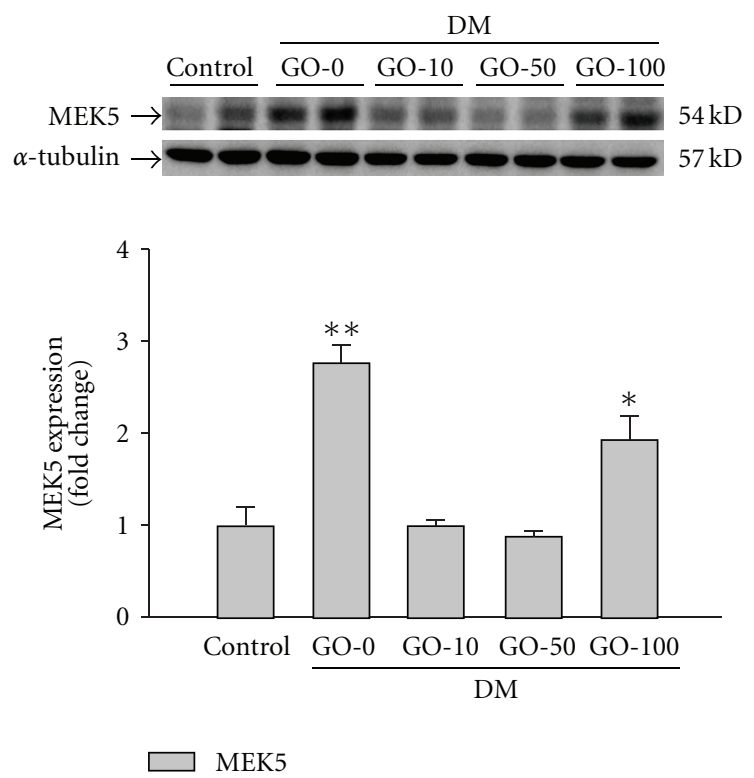

FIGURE 4: Detection of MEK5 protein levels from the left ventricles in control and diabetic rats, analyzed by western blotting. GO-0, $-10,-50$ and -100 represent the doses of $0,10,50$ and $100 \mathrm{mg}$ garlic oil per kg BW. Signal intensity was quantitated using a PhosphoImager. Equal loading was assessed with an anti $\alpha$-tubulin antibody. The average result \pm SE of three independent experiments is shown. ${ }^{*} P<.05,{ }^{* *} P<.01$ represent significant differences from control group. 

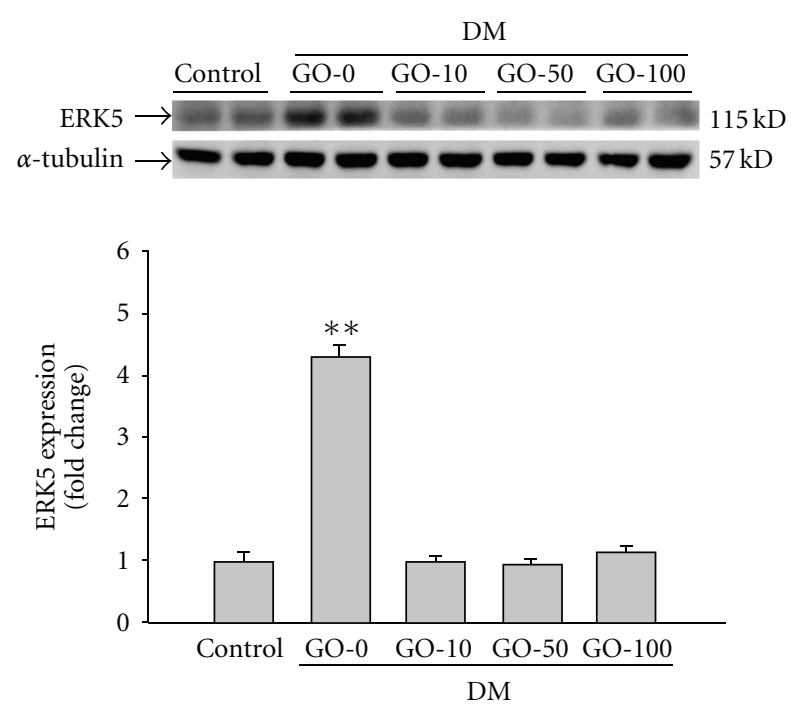

ERK5
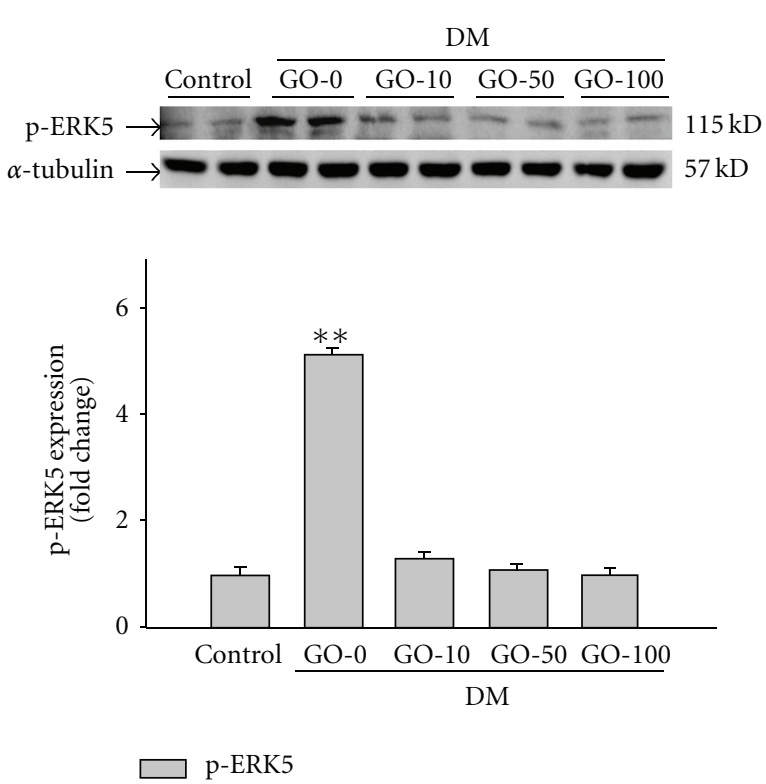

(b)

FIGURE 5: Detection of (a) ERK5 and (b) phosphorylated ERK5 protein levels from the left ventricles in control and diabetic rats, analyzed by western blotting. GO-0, -10, -50 and -100 represent the doses of $0,10,50$ and $100 \mathrm{mg}$ garlic oil per $\mathrm{kg}$ BW. Signal intensity was quantitated using a PhosphoImager. Equal loading was assessed with an anti $\alpha$-tubulin antibody. The average result \pm SE of three independent experiments is shown. ${ }^{* *} P<.01$ represent significant differences from control group.

development of diabetic cardiomyopathy. The up-regulation in both MEK5 and ERK5 was significantly decreased by supplement garlic oil (10, 50 and $\left.100 \mathrm{mg} \mathrm{kg}^{-1} \mathrm{BW}\right)$.

3.5. Pathologic Hypertrophy Marker ANP and BNP in the Diabetic Rat Left Ventricle was Reduced by Garlic Oil Supplement. To further understand whether the expression of proteins associated with cardiac pathologic hypertrophy was reduced by garlic oil treatment in the diabetic rat hearts, the pathologic hypertrophy markers such as ANP and BNP were analyzed by western blot (Figure 6). The left ventricle obtained from the diabetic rat hearts showed the significant expression of ANP (Figure 6(a)) and BNP (Figure 6(b)); however, the up-regulation in ANP and BNP in the hearts of diabetic rats was efficiently reduced by garlic oil supplement (10, 50 and $\left.100 \mathrm{mg} \mathrm{kg}^{-1} \mathrm{BW}\right)$. The results suggested that garlic oil significantly reduces the diabetesinduced characteristics of cardiac pathologic hypertrophy, improving the cardiac contractile function in the diabetic rats (Figure 1 and Table 1 ).

\section{Discussion}

The major findings of the present study can be summarized as follows: (i) STZ-induced diabetes leads to a decrease in $\mathrm{HR}$, cardiac contractile function, $\mathrm{CO}$ and contractile velocity in the cardiac muscle. Interestingly, all of these cardiac abnormalities induced by diabetes are improved by garlic oil treatment. (ii) Diabetic cardiomyopathy is structurally characterized by cardiac hypertrophy; in this study, we further identify molecular mechanisms involved in the diabetes-induced cardiac pathologic hypertrophy. Cardiac hypertrophy-related MAPKs (e.g., p38, JNK and ERK1/2) and IL-6/MEK5/ERK5 signaling pathways were greatly activated, which resulted in the expression of pathologic hypertrophy response markers such as ANP and BNP in the heart of diabetic rats. (iii) However, up-regulated activity in MAPKs (p38, JNK and ERK1/2), IL-6/MEK5/ERK5 signaling cascade and the expression of pathologic hypertrophy markers (ANP and BNP) were significantly inhibited when supplying garlic oil (10, 50 and $\left.100 \mathrm{mg} \mathrm{kg}^{-1} \mathrm{BW}\right)$. The results suggest that garlic oil possesses the potential cardioprotective effects for heart from diabetic cardiomyopathy (Figure 7).

Recent data from the Acute Decompensated Heart Failure National Registry demonstrates that $\sim 44 \%$ of patients with decompensated heart failure suffer from DM [50]. Pathophysiology of DM includes hypoinsulinemia, hyperglycemia, cardiac hypertrophy and a cardiomyopathy that is characterized by the presence of diastolic and/or systolic contractile dysfunction. Prolonged cardiac hypertrophy has been reported to be associated with the decompensation of heart function, the development of heart failure and sudden death in humans $[12-14,51]$. Because of the side effects of Western drugs, a large number of studies have focused on the effects of natural products on cardiovascular protection. Various oriental herb extracts or dietary supplement have been adopted for preventing cardiovascular abnormalities or disorders, for example, Li-Fu Formula for reducing cardiac apoptosis [51]; Buyang Huanwu Decoction for protection from ischemic heart disease [52]; fermented wheat germ 

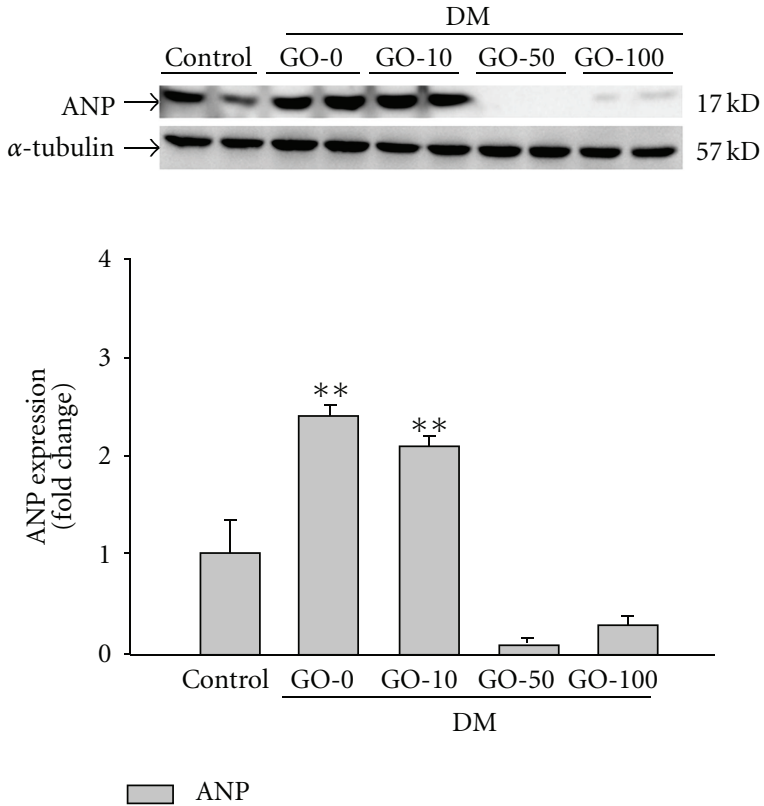

(a)
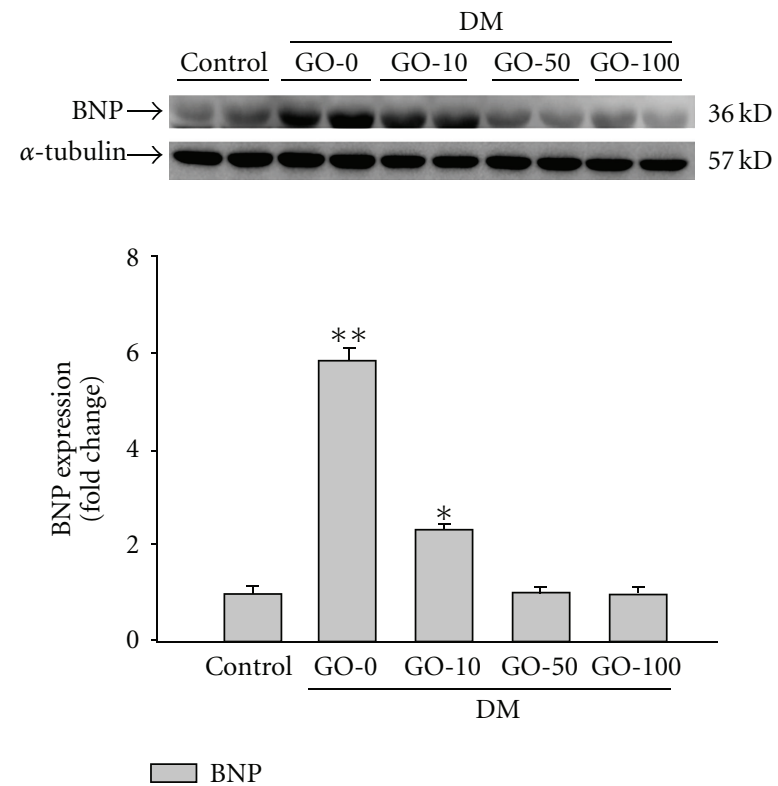

(b)

FIGURE 6: Detection of pathologic hypertrophy marker (a) ANP and (b) BNP protein level from the left ventricles in control and diabetic rats, analyzed by western blotting. GO-0, $-10,-50$ and -100 represent the doses of $0,10,50$ and $100 \mathrm{mg}$ garlic oil per kg BW. Signal intensity was quantitated using a PhosphoImager. Equal loading was assessed with an anti $\alpha$-tubulin antibody. The average result \pm SE of three independent experiments is shown. ${ }^{*} P<.05,{ }^{*} P<.01$ represent significant differences from control group.

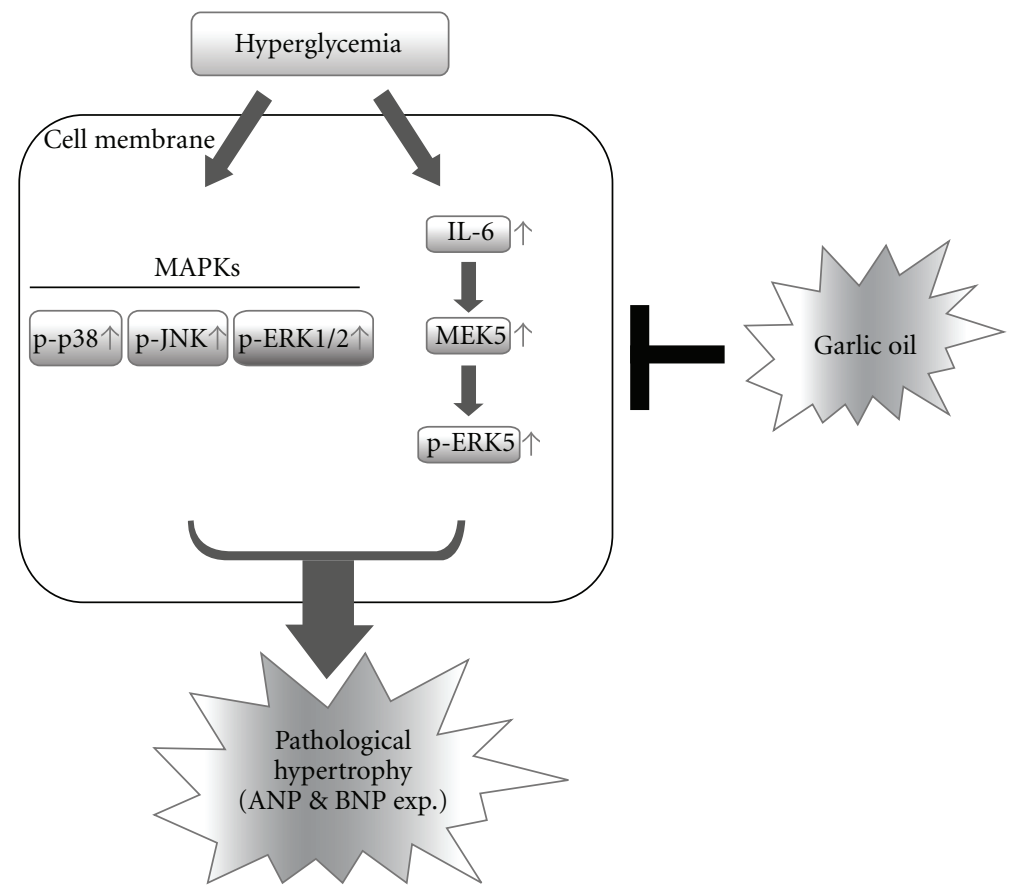

FIGURE 7: A schematic representation showing garlic oil ameliorates cardiac pathologic hypertrophy and subsequent cardiac dysfunction in rats with diabetes by down-regulating the activities of MAPKs (p38, JNK and ERK1/2) and IL-6/MEK5/ERK5 signaling pathways. Hyperglycemia greatly activates signaling pathways of MAPK (e.g., p38, JNK and ERK1/2) and IL-6/MEK5/ERK5, simultaneously, in the hearts of diabetic rats. These activated signaling pathways significantly induce the development of cardiac pathologic hypertrophy and the expressions of pathologic hypertrophy response genes such as ANP and BNP. In diabetic rats, treatment involving garlic oil reduces the hyperglycemia-cardiac pathologic hypertrophy and improves the heart function by efficiently de-activating MAPK (p38, JNK and ERK1/2) and IL-6/MEK5/ERK5 signaling pathways. 
extract (Avemar) for attenuating chronic hypertension, diabetes or metabolic syndrome-induced cardiovascular symptoms [53]; Tanshinone IIA for treatment of cardiovascular disorders [54]; and garlic extract for improving cardiac functions [55-57]. Garlic extract treatment shows some beneficial effects on modulating the HR, rhythm and force of cardiac contraction [55]. Garlic supplement significantly reduced HR during peak exercise and work load upon the heart, resulting in better exercise tolerance in patients with coronary artery disease [56, 58]. Garlic has a significant blood-pressure-lowering effect by reducing the activity of angiotensin-converting enzyme [57] and has protective effects on blocking hypoxic pulmonary hypertension in vivo and attenuating age-related increases in aortic stiffness [59]. In this study, we successfully used the STZ-induced diabetic rats to mimic diabetic human with features of cardiac dysfunction, for example, a decrease in FS and EF [60], and an increase in LVESD [61]. STZ-induced diabetes leads to a decrease in cardiac contractile function, $\mathrm{CO}$ and contractile velocity in the cardiac muscle. In this STZ-induced diabetic rat model, we observed that the upregulation of cardiac pathologic hypertrophy markers ANP and BNP in the diabetic rat hearts was significantly inhibited by garlic oil supplement (10, 50 and $\left.100 \mathrm{mg} \mathrm{kg}^{-1} \mathrm{BW}\right)$. Garlic oil supplement indeed improves HR, cardiac contractile function, $\mathrm{CO}$ and contractile velocity in the diabetic rat hearts. The results suggest that garlic oil improves cardiac function of the diabetic rats by alleviating the development of cardiac hypertrophy. In the clinical study, the evaluation of garlic oil effect on cardiac protection in diabetic patients is proceeding to confirm the present study.

Evidences show that the stimulation of cardiomyocyte hypertrophic growth like other environmental stresses such as osmotic stress, DNA damage and ultraviolet radiation results in the activation of protein kinase cascades, which in turn activate MAPKs such as p38 MAPK, JNK and EKR1/2 [62]. These serine-threonine kinases have been shown to phosphorylate the important downstream mediators that participate in cellular regulations such as cell proliferation, cell differentiation and cell growth process including cardiac hypertrophy $[20,21,23,26,28,31,32,63]$. In the present study, we found that increased phosphorylation/activation of p38, JNK and ERK1/2 was detected in the left ventricle of the diabetic rat hearts. The findings suggest that increased activity of MAPKs such as p38, JNK and ERK1/2 participates in the cardiac pathologic hypertrophy in diabetic rat hearts.

Overexpressed IL-6 in the myocardium as a result of AMI appears to play a central role in pathogenesis of cardiac hypertrophy [33]. Activated MEK5/ERK5 signaling pathway by IL-6 family cytokines has been reported to lead to the eccentric cardiac hypertrophy that progresses to dilated cardiomyopathy and sudden death $[34,64]$. In the present study, the left ventricles from diabetic rat hearts showed a significant up-regulation of IL-6, MEK5 and ERK5, suggesting that activated IL-6/MEK5/ERK5 signaling cascade participate in the diabetes-induced pathologic hypertrophy. We further found that the activated MAPKs (e.g., p38, JNK and ERK1/2) and IL-6/MEK5/ERK5 signaling pathway in the diabetic rat hearts were significantly inhibited when applying garlic oil supplement. These findings suggest that garlic oil improves heart function by greatly modifying the intracardiac activity of MAPKs (e.g., p38, JNK and ERK1/2) and IL-6/MEK5/ERK5 signaling pathways.

However, in the present study we also found that MEK5 protein in left ventricle was increased when STZ-induced DM rats were treated with garlic oil $\left(100 \mathrm{mg} \mathrm{kg}^{-1} \mathrm{BW}\right.$; GO$100)$. We speculated that garlic oil treatment more than GO100 dosage may initiate some side effect in left ventricle. More future studies are needed to investigate the side effect in myocardial cells treated with over-dosage of garlic oil. In the present study, we found that garlic oil treatment improves heart function without significant recovery from BW and the level of blood glucose in STZ-induced DM rats. Besides antioxidative $[43,65]$ and antiglycative [65] properties, we speculated that survival factors in cardiac cells of left ventricle are up-regulated by garlic oil treatment to protect heart from hyperglycemia-induced injury in STZ-induced DM rats. We will further examine the effect of garlic oil on expression of survival factors in myocardial cells.

In conclusion, our findings show that garlic oil supplement to diabetic hearts leads to several alterations at multiple levels, including the improvement of cardiac contractile functions, the down-regulation of cardiac-hypertrophyrelated signaling activities and the decrease in expression of cardiac pathologic hypertrophy response genes ANP and BNP. Garlic oil indeed shows the cardioprotective potential for heart from diabetic cardiomyopathy.

\section{Funding}

National Science Council of Republic of China (grant NSC96-2320-B-039-035-MY3). The authors acknowledge the support of the China Medical University (CMU95-176). This study is also supported by Taiwan Department of Health Clinical Trial and Research Center of Excellence (DOH99TD-B-111-004) and in part by Taiwan Department of Health Cancer Research Center of Excellence (DOH99-TD-C-111005).

\section{Acknowledgments}

The authors want to specially thank Dr Cooper for his kind and constructive advice. C.-Y. Huang, B.-S. Tzang, and W.W. Kuo contributed equally to this work.

\section{References}

[1] Cataloguing-in-Publication WHO Library Data, "WHO Library Cataloguing-in-Publication Data, Diabetes Action Now: An Initiative of the World Health Organization and the International Diabetes Federation," 2004.

[2] M. T. Johnstone and A. Veves, Diabetes and Cardiovascular Disease, Humana Press, Totowa, NJ, USA, 2nd edition, 2005.

[3] J. Price, S. Verma, and R.-K. Li, "Diabetic heart dysfunction: is cell transplantation a potential therapy?" Heart Failure Reviews, vol. 8, no. 3, pp. 213-219, 2003.

[4] Ö. Yildirim and Z. Büyükbingöl, "Effect of cobalt on the oxidative status in heart and aorta of streptozotocin-induced diabetic rats," Cell Biochemistry and Function, vol. 21, no. 1, pp. 27-33, 2003. 
[5] S. Muruganandan, S. Gupta, M. Kataria, J. Lal, and P. K. Gupta, "Mangiferin protects the streptozotocin-induced oxidative damage to cardiac and renal tissues in rats," Toxicology, vol. 176, no. 3, pp. 165-173, 2002.

[6] B. Feng, S. Chen, J. Chiu, B. George, and S. Chakrabarti, "Regulation of cardiomyocyte hypertrophy in diabetes at the transcriptional level," American Journal of PhysiologyEndocrinology and Metabolism, vol. 294, no. 6, pp. E1119E1126, 2008.

[7] B. H. Lorell and B. A. Carabello, "Left ventricular hypertrophy: pathogenesis, detection, and prognosis," Circulation, vol. 102, no. 4, pp. 470-479, 2000.

[8] E. N. Olson and M. D. Schneider, "Sizing up the heart: development redux in disease," Genes and Development, vol. 17, no. 16, pp. 1937-1956, 2003.

[9] J. D. Molkentin and G. W. Dorn II, "Cytoplasmic signaling pathways that regulate cardiac hypertrophy," Annual Review of Physiology, vol. 63, pp. 391-426, 2001.

[10] P. H. Sugden and A. Clerk, "Cellular mechanisms of cardiac hypertrophy," Journal of Molecular Medicine, vol. 76, no. 11, pp. 725-746, 1998.

[11] Y. Wang, B. Su, V. P. Sah, J. H. Brown, J. Han, and K. R. Chien, "Cardiac hypertrophy induced by mitogen-activated protein kinase kinase 7, a specific activator for c-Jun NH2-terminal kinase in ventricular muscle cells," Journal of Biological Chemistry, vol. 273, no. 10, pp. 5423-5426, 1998.

[12] J. A. Towbin and N. E. Bowles, "The failing heart," Nature, vol. 415, no. 6868, pp. 227-233, 2002.

[13] J. J. Hunter and K. R. Chien, "Signaling pathways for cardiac hypertrophy and failure," New England Journal of Medicine, vol. 341, no. 17, pp. 1276-1283, 1999.

[14] D. L. Mann, "Mechanisms and models in heart failure: a combinatorial approach," Circulation, vol. 100, no. 9, pp. 999 1008, 1999.

[15] D. Levy, R. J. Garrison, D. D. Savage, W. B. Kannel, and W. P. Castelli, "Prognostic implications of echocardiographically determined left ventricular mass in the Framingham Heart Study," New England Journal of Medicine, vol. 322, no. 22, pp. 1561-1566, 1990.

[16] M. H. Drazner, J. E. Rame, E. K. Marino et al., "Increased left ventricular mass is a risk factor for the development of a depressed left ventricular ejection fraction within five years: the Cardiovascular Health Study," Journal of the American College of Cardiology, vol. 43, no. 12, pp. 2207-2215, 2004.

[17] N. Frey and E. N. Olson, "Cardiac hypertrophy: the good, the bad, and the ugly," Annual Review of Physiology, vol. 65, pp. 45-79, 2003.

[18] P. H. Sugden and A. Clerk, 'Stress-responsive' mitogenactivated protein kinases (c-Jun $\mathrm{N}$-terminal kinases and p38 mitogen-activated protein kinases) in the myocardium," Circulation Research, vol. 83, no. 4, pp. 345-352, 1998.

[19] J.-I. Abe, C. P. Baines, and B. C. Berk, "Role of mitogenactivated protein kinases in ischemia and reperfusion injury: the good and the bad," Circulation Research, vol. 86, no. 6, pp. 607-609, 2000.

[20] Y.-C. Cheng, L.-M. Chen, M.-H. Chang et al., "Lipopolysaccharide upregulates uPA, MMP-2 and MMP-9 via ERK1/2 signaling in H9c2 cardiomyoblast cells," Molecular and Cellular Biochemistry, vol. 325, no. 1-2, pp. 15-23, 2009.

[21] P. E. Glennon, S. Kaddoura, E. M. Sale, G. J. Sale, S. J. Fuller, and P. H. Sugden, "Depletion of mitogenactivated protein kinase using an antisense oligodeoxynu- cleotide approach downregulates the phenylephrine-induced hypertrophic response in rat cardiac myocytes," Circulation Research, vol. 78, no. 6, pp. 954-961, 1996.

[22] O. F. Bueno, E. van Rooij, J. D. Molkentin, P. A. Doevendans, and L. J. de Windt, "Calcineurin and hypertrophic heart disease: novel insights and remaining questions," Cardiovascular Research, vol. 53, no. 4, pp. 806-821, 2002.

[23] T.-L. Yue, J.-L. Gu, C. Wang et al., "Extracellular signalregulated kinase plays an essential role in hypertrophic agonists, endothelin-1 and phenylephrine-induced cardiomyocyte hypertrophy," Journal of Biological Chemistry, vol. 275, no. 48, pp. 37895-37901, 2000.

[24] Y. Takeishi, Q. Huang, J.-I. Abe et al., "Src and multiple MAP kinase activation in cardiac hypertrophy and congestive heart failure under chronic pressure-overload: comparison with acute mechanical stretch," Journal of Molecular and Cellular Cardiology, vol. 33, no. 9, pp. 1637-1648, 2001.

[25] A. Clerk, A. Michael, and P. H. Sugden, "Stimulation of the p38 mitogen-activated protein kinase pathway in neonatal rat ventricular myocytes by the $G$ protein-coupled receptor agonists, endothelin-1 and phenylephrine: a role in cardiac myocyte hypertrophy?" Journal of Cell Biology, vol. 142, no. 2, pp. 523-535, 1998.

[26] T. M. Behr, M. Berova, C. P. Doe et al., "p38 mitogenactivated protein kinase inhibitors for the treatment of chronic cardiovascular disease," Current Opinion in Investigational Drugs, vol. 4, no. 9, pp. 1059-1064, 2003.

[27] I. Komuro, S. Kudo, T. Yamazaki, Y. Zou, I. Shiojima, and Y. Yazaki, "Mechanical stretch activates the stress-activated protein kinases in cardiac myocytes," FASEB Journal, vol. 10, no. 5, pp. 631-636, 1996.

[28] G. Choukroun, R. Hajjar, J. M. Kyriakis, J. V. Bonventre, A. Rosenzweig, and T. Force, "Role of the stress-activated protein kinases in endothelin-induced cardiomyocyte hypertrophy," Journal of Clinical Investigation, vol. 102, no. 7, pp. 1311-1320, 1998.

[29] M. Teresa Ramirez, X.-L. Zhao, H. Schulman, and J. H. Brown, "The nuclear $\delta(\mathrm{B})$ isoform of $\mathrm{Ca} 2+/$ calmodulindependent protein kinase II regulates atrial natriuretic factor gene expression in ventricular myocytes," Journal of Biological Chemistry, vol. 272, no. 49, pp. 31203-31208, 1997.

[30] M. Yano, S. Kim, Y. Izumi, S. Yamanaka, and H. Iwao, "Differential activation of cardiac c-jun amino-terminal kinase and extracellular signal-regulated kinase in angiotensin IImediated hypertension," Circulation Research, vol. 83, no. 7, pp. 752-760, 1998.

[31] G. Choukroun, R. Hajjar, S. Fry et al., "Regulation of cardiac hypertrophy in vivo by the stress-activated protein kinases/cJun NH2-terminal kinases," Journal of Clinical Investigation, vol. 104, no. 4, pp. 391-398, 1999.

[32] M. A. Bogoyevitch, J. Gillespie-Brown, A. J. Ketterman et al., "Stimulation of the stress-activated mitogen-activated protein kinase subfamilies in perfused heart: p38/RK mitogenactivated protein kinases and c-Jun $\mathrm{N}$-terminal kinases are activated by ischemia/reperfusion," Circulation Research, vol. 79, no. 2, pp. 162-173, 1996.

[33] T. Kanda and T. Takahashi, "Interleukin-6 and cardiovascular diseases," Japanese Heart Journal, vol. 45, no. 2, pp. 183-193, 2004.

[34] R. L. Nicol, N. Frey, G. Pearson, M. Cobb, J. Richardson, and E. N. Olson, "Activated MEK5 induces serial assembly of sarcomeres and eccentric cardiac hypertrophy," EMBO Journal, vol. 20, no. 11, pp. 2757-2767, 2001. 
[35] L. D. Brace, "Cardiovascular benefits of garlic (Allium sativum L)," Journal of Cardiovascular Nursing, vol. 16, no. 4, pp. 33-49, 2002.

[36] K. Rahman and G. M. Lowe, "Garlic and cardiovascular disease: a critical review," Journal of Nutrition, vol. 136, no. 3, pp. 736S-740S, 2006.

[37] M. J. A. Williams, W. H. F. Sutherland, M. P. McCormick, D. J. Yeoman, and S. A. de Jong, "Aged garlic extract improves endothelial function in men with coronary artery disease," Phytotherapy Research, vol. 19, no. 4, pp. 314-319, 2005.

[38] I. A. Sobenin, V. V. Pryanishnikov, L. M. Kunnova, E. A. Rabinovich, and A. N. Orekhov, "Allicor efficacy in lowering the risk of ischemic heart disease in primary prophylaxis," Terapevticheskii Arkhiv, vol. 77, no. 12, pp. 9-13, 2005.

[39] S. K. Banerjee, P. K. Mukherjee, and S. K. Maulik, "Garlic as an antioxidant: the good, the bad and the ugly," Phytotherapy Research, vol. 17, no. 2, pp. 97-106, 2003.

[40] E. A. Ryan, M. E. Pick, and C. Marceau, "Use of alternative medicines in diabetes mellitus," Diabetic Medicine, vol. 18, no. 3, pp. 242-245, 2001.

[41] F. M. El-Demerdash, M. I. Yousef, and N. I. A. El-Naga, "Biochemical study on the hypoglycemic effects of onion and garlic in alloxan-induced diabetic rats," Food and Chemical Toxicology, vol. 43, no. 1, pp. 57-63, 2005.

[42] T. Baluchnejadmojarad and M. Roghani, "Endotheliumdependent and -independent effect of aqueous extract of garlic on vascular reactivity on diabetic rats," Fitoterapia, vol. 74, no. 7-8, pp. 630-637, 2003.

[43] M. M. Anwar and A.-R. Meki, "Oxidative stress in streptozotocin-induced diabetic rats: effects of garlic oil and melatonin," Comparative Biochemistry and Physiology A: Molecular and Integrative Physiology, vol. 135, no. 4, pp. 539547, 2003.

[44] T. Baluchnejadmojarad and M. Roghani, "Garlic extract attenuates time-dependent changes in the reactivity of isolated aorta in streptozotocin-diabetic rats," Life Sciences, vol. 73, no. 18, pp. 2281-2289, 2003.

[45] M. G. Duncan, "The effects of nutritional supplements on the treatment of depression, diabetes, and hypercholesterolemia in the renal patient," Journal of Renal Nutrition, vol. 9, no. 2, pp. 58-62, 1999.

[46] H.-W. Chen, J.-J. Yang, C.-W. Tsai et al., "Dietary fat and garlic oil independently regulate hepatic cytochrome P450 2B1 and the placental form of glutathione S-transferase expression in rats," Journal of Nutrition, vol. 131, no. 5, pp. 1438-1443, 2001.

[47] A. Junod, A. E. Lambert, W. Stauffacher, and A. E. Renold, "Diabetogenic action of streptozotocin: relationship of dose to metabolic response," Journal of Clinical Investigation, vol. 48, no. 11, pp. 2129-2139, 1969.

[48] M. M. Bradford, "A rapid and sensitive method for the quantitation of microgram quantities of protein utilizing the principle of protein dye binding," Analytical Biochemistry, vol. 72, no. 1-2, pp. 248-254, 1976.

[49] K. Kaneko, T. Kanda, T. Yokoyama et al., "Expression of interleukin-6 in the ventricles and coronary arteries of patients with myocardial infarction," Research Communications in Molecular Pathology and Pharmacology, vol. 97, no. 1, pp. 312, 1997.

[50] G. C. Fonarow, "The Acute Decompensated Heart Failure National Registry (ADHERE ${ }^{T M}$ ): opportunities to improve care of patients hospitalized with acute decompensated heart failure," Reviews in Cardiovascular Medicine, vol. 4, supplement 7, pp. S21-S30, 2003.
[51] W. W. Kuo, T. C. Hsu, M. H. Chain et al., "Attenuated cardiac mitochondrial-dependent apoptotic effects by Li-Fu formula in hamsters fed with a hypercholesterol diet," Evidence-Based Complementary and Alternative Medicine. In press.

[52] G. Yang, Z. Fang, Y. Liu et al., "Protective effects of Chinese traditional medicine Buyang Huanwu decoction on myocardial injury," Evidence-Based Complementary and Alternative Medicine. In press.

[53] A. Iyer and L. Brown, "Fermented wheat germ extract (Avemar) in the treatment of cardiac remodeling and metabolic symptoms in rats," Evidence-Based Complementary and Alternative Medicine. In press.

[54] P. Chan, I. M. Liu, Y. X. Li, W. J. Yu, and J. T. Cheng, "Antihypertension induced by tanshinone IIA isolated from the roots of Salvia Miltiorrhiza," Evidence-Based Complementary and Alternative Medicine. In press.

[55] R. K. Yadav and N. S. Verma, "Effects of garlic (Allium sativum) extract on the heart rate, rhythm and force of contraction in frog: a dose-dependent study," Indian Journal of Experimental Biology, vol. 42, no. 6, pp. 628-631, 2004.

[56] M. Zahid Ashraf, M. E. Hussain, and M. Fahim, "Antiatherosclerotic effects of dietary supplementations of garlic and turmeric: restoration of endothelial function in rats," Life Sciences, vol. 77, no. 8, pp. 837-857, 2005.

[57] A. M. Sharifi, R. Darabi, and N. Akbarloo, "Investigation of antihypertensive mechanism of garlic in $2 \mathrm{~K} 1 \mathrm{C}$ hypertensive rat," Journal of Ethnopharmacology, vol. 86, no. 2-3, pp. 219224, 2003.

[58] S. K. Verma, V. Rajeevan, P. Jain, and A. Bordia, "Effect of garlic (Allium sativum) oil on exercise tolerance in patients with coronary artery disease," Indian Journal of Physiology and Pharmacology, vol. 49, no. 1, pp. 115-118, 2005.

[59] M. B. Fallon, G. A. Abrams, T. T. Abdel-Razek et al., "Garlic prevents hypoxic pulmonary hypertension in rats," American Journal of Physiology, vol. 275, no. 2, pp. L283-L287, 1998.

[60] E. Al-Shawaf, A. Ayed, I. Vislocky, B. Radomir, N. Dehrab, and R. Tarazi, "Levosimendan or milrinone in the type 2 diabetic patient with low ejection fraction undergoing elective coronary artery surgery," Journal of Cardiothoracic and Vascular Anesthesia, vol. 20, no. 3, pp. 353-357, 2006.

[61] J. Escaned, H. Colmenárez, M. C. Ferrer et al., "Diastolic dysfunction in diabetic patients assessed with doppler echocardiography: relationship with coronary atherosclerotic burden and microcirculatory impairment," Revista Espanola de Cardiologia, vol. 62, no. 12, pp. 1395-1403, 2009.

[62] M. Karin and Y. Ben-Neriah, "Phosphorylation meets ubiquitination: the control of NF- $\kappa \mathrm{B}$ activity," Annual Review of Immunology, vol. 18, pp. 621-663, 2000.

[63] R. Dash, A. G. Schmidt, A. Pathak et al., "Differential regulation of p38 mitogen-activated protein kinase mediates gender-dependent catecholamine-induced hypertrophy," Cardiovascular Research, vol. 57, no. 3, pp. 704-714, 2003.

[64] S. J. Cameron, S. Itoh, C. P. Baines et al., "Activation of big MAP kinase 1 (BMK1/ERK5) inhibits cardiac injury after myocardial ischemia and reperfusion," FEBS Letters, vol. 566, no. 1-3, pp. 255-260, 2004.

[65] C.-N. Huang, J.-S. Horng, and M.-C. Yin, "Antioxidative and antiglycative effects of six organosulfur compounds in lowdensity lipoprotein and plasma," Journal of Agricultural and Food Chemistry, vol. 52, no. 11, pp. 3674-3678, 2004. 


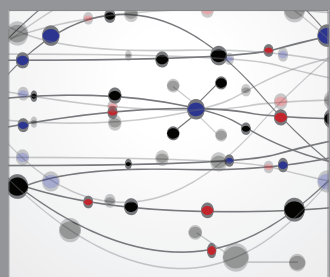

The Scientific World Journal
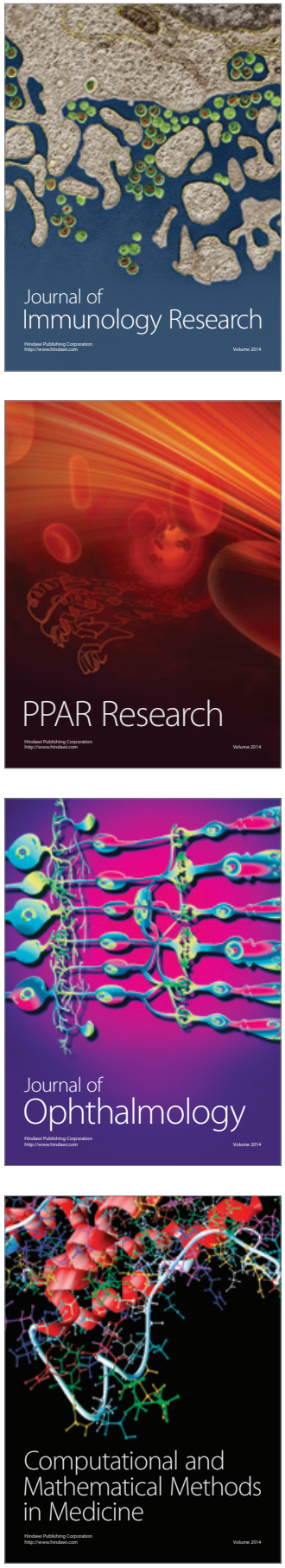

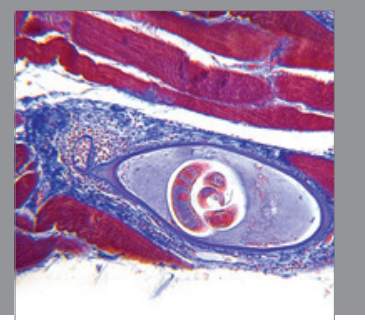

Gastroenterology

Research and Practice
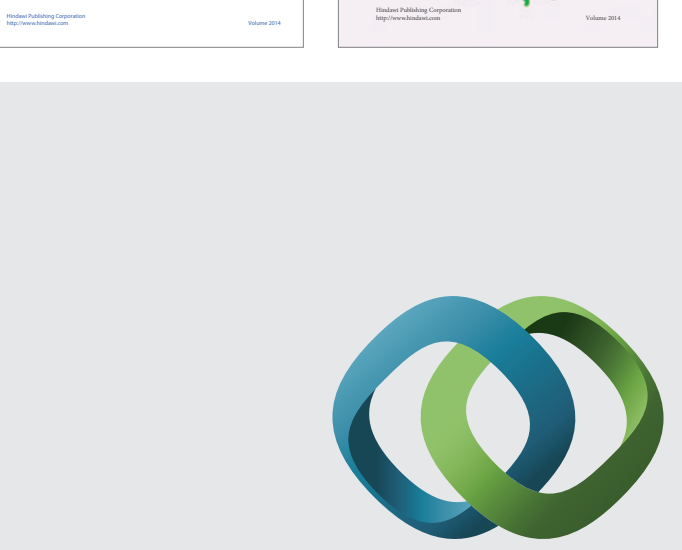

\section{Hindawi}

Submit your manuscripts at

http://www.hindawi.com
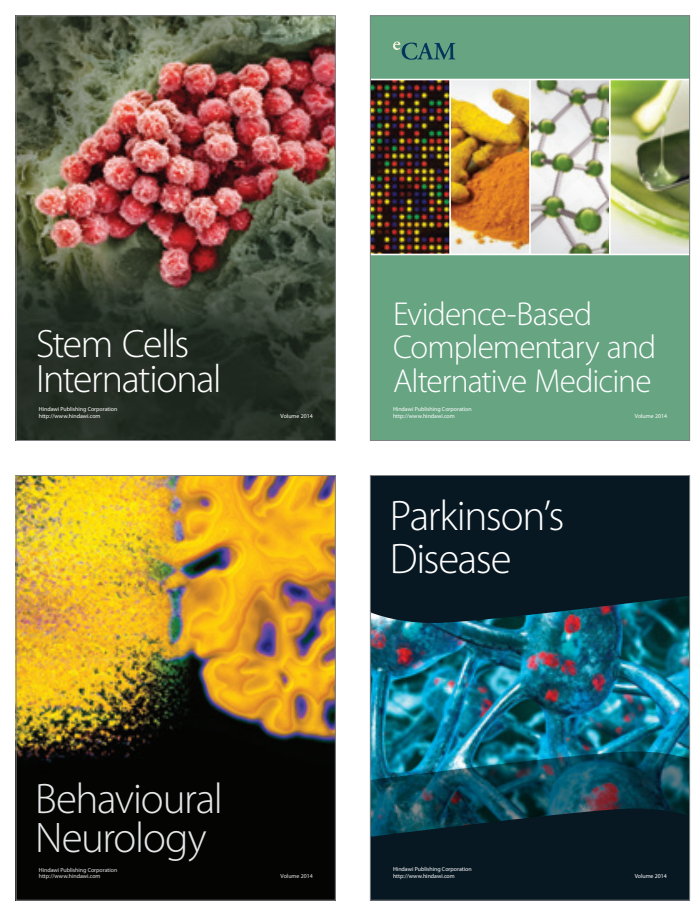

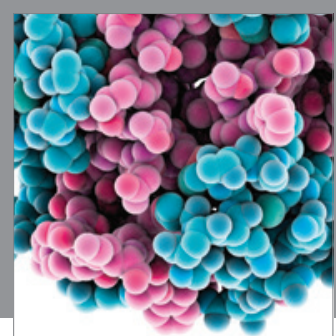

Journal of
Diabetes Research

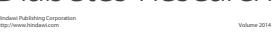

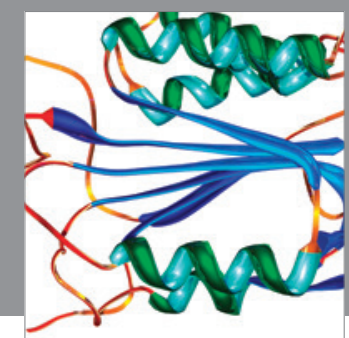

Disease Markers
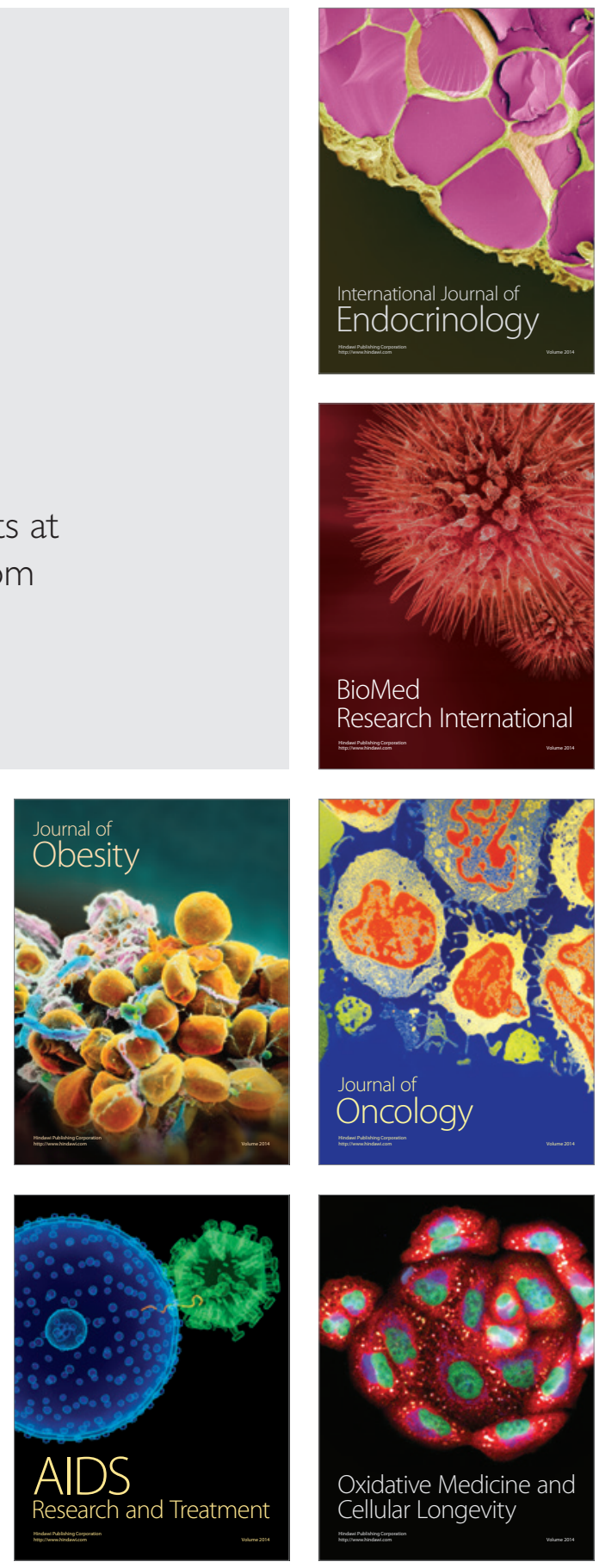